\title{
A MORTE COMO ELEMENTO CULTURAL MEXICANO EM PEDRO PÁRAMO, DE JUAN RULFO
}

\author{
Ana Paula Cantarelli ${ }^{1}$
}

\begin{abstract}
Resumo: Pedro Páramo (1955), de Juan Rulfo, desde sua publicação tem sido alvo de inúmeros estudos desenvolvidos por pesquisadores de diferentes áreas do conhecimento (história, sociologia, filosofia, etc.). Neste texto, buscou-se elaborar uma proposta de leitura a partir do reconhecimento da morte, símbolo nacional mexicano, como um elemento constituinte da estrutura narrativa desse romance, com a intenção de ampliar o campo de análises já delineado ao redor dessa obra.
\end{abstract}

Palavras-chave: morte; símbolo nacional; estrutura narrativa.

Resumen: Pedro Páramo (1955), de Juan Rulfo, desde su publicación es objeto de estudio de muchos investigadores de distintas áreas del conocimiento (historia, sociología, filosofía, etc.). En ese texto, se buscó desarrollar una propuesta de lectura a partir del reconocimiento de la muerte, símbolo nacional mexicano, como un elemento integrante de la estructura narrativa de esa novela, con el objetivo de ampliar el campo de análisis ya establecido alrededor de esa obra.

Palabras-clave: muerte; símbolo nacional; estructura narrativa.

\section{Considerações Iniciais}

No México, a morte erige-se como um símbolo nacional, ganhando destaque na estruturação identitária desse Estado. Exemplos disso estão no grande número de Catrinas $^{2}$ encontradas em todos os espaços públicos mexicanos, nas constantes referências a deuses pré-colombianos, como a deusa Coatlicue ${ }^{3}$, e nos "días de muertos", uma das maiores festas populares nacionais. As referências à morte, nesse país, surgem organizadas de maneira complexa a partir de elementos europeus (trazidos pelos

\footnotetext{
${ }_{2}^{1}$ Doutora em Estudos Literários pela Universidade Federal de Santa Maria (UFSM).

2 La Catrina, originalmente denominada de La Calavera Garbancera, é uma figura criada por José Guadalupe Posada e batizada por Diego Rivera. Segundo a cultura mexicana, a figura de "La Catrina", com seus adornos e ossos expostos, relaciona-se intimamente com a morte. Seu ar jocoso e seus acessórios amenizam o aspecto terrífico que a mandíbula saliente e o vazio dos olhos possam causar, associando vida e morte em uma mesma figura.

${ }^{3}$ Cuatlicue, na mitologia asteca, era considerada a deusa da vida e da morte. Ao mesmo tempo em que estava associada à fertilidade, trazia em suas vestes caveiras como adornos. Cuatlicue era uma deusa feroz, sedenta por sacrifícios humanos. Possuía garras afiadas nas mãos e nos pés remetendo à ferocidade do jaguar, e as serpentes que a cobriam - fazendo inclusive parte da sua anatomia - simbolizavam a humanidade.
} 
espanhóis) e de elementos indígenas (povos que habitavam as terras mexicanas), assumindo traços de ambos os grupos étnicos. As culturas pré-colombianas possuíam uma relação com a morte que divergia da que a lgreja Católica e, por conseguinte, os espanhóis, possuíam. Embora a Igreja buscasse subjugar toda forma de manifestação religiosa que se diferenciasse da sua, no território mexicano, os indígenas conseguiram ocultar e dissimular suas práticas mantendo parte de suas crenças, adaptando-as às imposições católicas. Tem-se notícia de que, em muitas crenças pré-colombianas, 0 sacrifício humano era bem acolhido, como uma maneira de realizar oferendas aos deuses em troca de boas colheitas e de saúde para todo o grupo o que, de certa maneira, estabelece uma relação de "simpatia" para com a morte.

Com a chegada dos espanhóis, aldeias inteiras foram dizimadas durante os embates pela posse das terras: "nenhuma muralha, nenhum gineceu teria podido preservar do choque culturas e homens. Os índios que tinham fugido do México divulgavam narrativas de terror, descrevendo cadáveres que juncavam as calçadas e boiavam nas águas lamacentas do lago" (BERNAND; GRUZINSKI, 2006, p. 132). Com o passar do tempo, e a delimitação dos territórios, os embates diminuíram. Em 1876, com o governo de Porfirio Díaz, a tradição de execuções sumárias foi superada. Entretanto, com os confrontos decorrentes da revolução mexicana, voltam a ocorrer inúmeras mortes, formando-se, inclusive, esquadras de fuzilamento. As perdas humanas ocasionadas pelo processo revolucionário fazem crer que o mexicano está imerso em processos conflitivos constantes e que a morte é uma "companheira" com a qual é necessário conviver.

O fato da primeira revolução popular latino-americana do século XX ter ocorrido no México; o fato de diferentes classes sociais terem participado da revolução e o reconhecimento dos princípios ideológicos que nortearam os confrontos tornaram-se, para o povo mexicano, de forma geral, motivo de orgulho e de distinção: "los abuelos nos castigaban cuando la escribíamos con minúsculas, porque como país debíamos agradecer la lucha de esos héroes con el respeto, y sobre todo la distancia teatral del público que observa, que impone las mayúsculas"4 (MANZUR, 2011, p. 391). Quando, em 1955, Juan Rulfo publicou pela primeira vez Pedro Páramo, o México viu as "glórias"

\footnotetext{
4 Tradução nossa: "os avós nos castigavam quando a escrevíamos com minúsculas, porque como país devíamos agradecer a luta desses heróis com o respeito, e, sobretudo, com a distância teatral do público que observa, que impõe as maiúsculas".
} 
alcançadas com a revolução sucumbirem frente a um cenário de abandono, de deterioração e de ruína apresentado nas páginas da narrativa. Segundo Klahn (1996, p. 527), "en Rulfo la búsqueda de lo mexicano lo lleva a un cuestionamiento crítico de la historia. Al mitificar, al recrear desde la imaginación situaciones y personajes concretos, edifica símbolos y al darles ese realce desmitifica los estereotipos nacionales y los triunfos de la revolución" 5 . Rulfo desconstrói, em sua narrativa, a visão épica da revolução, desmitificando e destruindo a glorificação do valor da força bruta.

Em Pedro Páramo, em um cenário árido, de destruição, onde até as palavras são econômicas, curtas, secas, a morte encontra vãos, encontra espaço. Mas, em seu romance, Rulfo faz mais do que delinear um símbolo nacional mexicano, ele o escancara através de personagens mortas que assumem o controle da narrativa, que revelam ao leitor suas histórias, fazendo-o escutar suas vozes. A morte ocupa o primeiro plano, evocando o passado e a história dos mexicanos, a identidade do país. Neste estudo, buscou-se delinear uma proposta de leitura de Pedro Páramo a partir do reconhecimento da morte, enquanto símbolo nacional mexicano, como um elemento estruturador do romance. Acredita-se que dessa forma será possível desenvolver uma interpretação que atualize dentro do texto a história e a identidade mexicanas.

\section{Pedro Páramo: organização do romance}

Pedro Páramo, de autoria do mexicano Juan Rulfo, foi publicado pela primeira vez em 1955. A narrativa inicia com a morte de Dolores Preciado, mãe de Juan Preciado. Juan cresceu ouvindo as histórias que a mãe contava sobre Comala e sobre sua relação com Pedro. Em seu leito de morte, Dolores fez o filho prometer que viajaria para Comala em busca de Pedro Páramo e dos bens que a família Preciado havia deixado naquele povoado. Sentindo que fora abandonada, Dolores imbui Juan de cobrar tudo o que Ihes era devido: "No vayas a pedirle nada. Exígele lo nuestro. Lo que estuvo obligado a darme

\footnotetext{
${ }^{5}$ Tradução nossa: "em Rulfo a busca do mexicano o leva a um questionamento crítico da história. Ao mitificar, ao recriar a partir da imaginação situações e personagens concretos, edifica símbolos e, ao darlhes esse realce, desmitifica os estereótipos nacionais e os triunfos da revolução".
} 
y nunca me dio... El olvido en que nos tuvo, mi hijo, cóbraselo caro"6 (RULFO, 2009, p. 05). Nas histórias que contava, Dolores apresentava Comala como um lugar próspero, fértil, vivo. No entanto, quando chegou ao povoado, Juan se deparou com um lugar seco, árido, habitado pelos espectros dos moradores mortos. Pedro Páramo e Comala estavam mortos.

Nas páginas iniciais do romance, antes de chegar a Comala, é a voz de Juan Preciado que conduz a narrativa. Depois que o filho de Dolores ingressou no povoado, outras vozes começaram a surgir no texto: há trechos de descrições de Comala feitos por Dolores para Juan; há passagens em primeira pessoa que podem ser atribuídas a Pedro Páramo, contendo recordações da sua infância e adolescência; há moradores mortos que, por diversas vezes, assumem a voz narrativa e ainda há um narrador em terceira pessoa que traz relatos sobre a vida e a história dos moradores de Comala que tiveram algum envolvimento com Pedro. Há passagens em que esses narradores são substituídos por diálogos entre as personagens. As vozes narrativas e os diálogos estão dispostos de modo que, ao mesmo tempo em que a viagem de Juan a Comala é relatada, o passado do povoado é revelado.

Juan morreu durante sua segunda noite em Comala. A história que foi iniciada com a busca de Preciado continua desenvolvendo-se mesmo após a morte deste. A partir desse ponto, são os monólogos de Dorotea e de Susana e a voz de um narrador em terceira pessoa que assumem o controle da narrativa, sendo essa última a que possui maior espaço e a que fecha o texto. O narrador em terceira pessoa é quem conta como os homens de Comala entraram na revolução, como o cura ingressou na Guerra Cristera e como Abundio matou Pedro. Tais ações são os elementos que selam o destino de Comala que, abandonada por Pedro desde a morte de Susana, vê sua história assumir um rumo de condenação.

Em sua viagem, Preciado buscava encontrar o pai. Contudo, Pedro já estava morto. O narrador que conta a história de Pedro é impessoal, ressaltando a distância existente entre o pai e o filho. Pedro Páramo subjugou o povoado em que vivia. Assim, encontrar um lugar ao lado do pai e fazer parte de Comala significa encontrar um lugar entre os subjugados. Sob esse viés, podemos considerar a busca de Juan como uma

\footnotetext{
${ }^{6}$ Tradução nossa: "Não lhe peças nada. Exige-lhe o que é nosso. Aquilo que esteve obrigado a dar-me e nunca me deu... O esquecimento em que nos teve, meu filho, cobra-lhe caro".
} 
demanda bem sucedida - pelo menos de forma parcial -, uma vez que ele encontrou seu lugar de filho de Pedro Páramo, de habitante de um povoado morto. A morte e a subjugação são as únicas heranças que Preciado ainda poderia reivindicar e, ao reivindicá-las, ele assumiu um lugar em Comala.

O fato de o pai de Juan estar morto dá um caráter particular à busca desde o início. Podemos ver o enredo pela ótica de um pai que, sem amar ninguém além de si, de Suzana San Juan e de Miguel Páramo, somente poderia tratar Juan como mais um dos tantos que ele já havia subjugado. Sob este aspecto, o pai já estava morto anteriormente para o filho. Assim, desde o início a busca já estaria fadada a não alcançar de forma satisfatória os anseios que a motivaram. Por esse viés, lemos a integração do filho ao solo de Comala como um ganho, mas não como um real encontro com o pai do qual ele só ouviu falar: Pedro não está entre os mortos que aparecem para Juan.

\section{A sedução da morte}

No México, a morte é tida como um símbolo nacional. Tal ato pode surpreender à primeira vista, pois, a partir do imaginário cristão e da concepção moderna de tempo, estabelecer a morte como um símbolo parece aniquilar a perspectiva de futuro, condenando a sociedade mexicana a uma espécie de perecimento gradual ou a uma estagnação na qual o presente reproduziria o passado sem qualquer projeção de futuro. Tal concepção "amputaria” a percepção de desenvolvimento ou ainda de avanço social, econômico e intelectual. Porém, o imaginário acerca da morte construído nesse país está intimamente atrelado à concepção pré-colombiana de morte das tribos indígenas e à concepção circular do tempo por elas adotada. A união desses dois imaginários (cristão e indígena mexicano) deu origem às configurações assumidas pela morte nesse país. Como indica Lomnitz (2006, p. 15), "la historia de México posee una cualidad fragmentaria; es una historia que tiene un claro antes y después - es decir, ora precolombina, ora moderna - y la historia moderna de México refleja y refracta esa 
fragmentación" "T. Tal fragmentação que, ao princípio, pode sugerir o estabelecimento e a perpetuação de dois momentos diametralmente opostos, quando observada de perto mostra uma interpenetração de crenças, de ritos e de mitos que constituem a percepção e o imaginário mexicanos sobre a morte.

Lomnitz (2006) defende que, atualmente, o México possui três totens nacionais ou figuras de filiação coletiva: a Virgem de Guadalupe, Benito Juárez e o esqueleto brincalhão que representa a morte. No caso do terceiro totem, os vínculos entre a morte e a sociedade mexicana não possuem uma origem fácil de ser apreendida, pois a violência e a própria morte estiveram presentes como um símbolo tutelar que acompanhou historicamente a formação e o desenvolvimento desse povo.

Entre os elementos e/ou ações empregados/ocorridas no processo de nacionalização mexicano, relacionados ao terceiro totem, apresentaremos alguns que auxiliam de forma mais pontual na compreensão da estruturação desse símbolo nacional. Em primeiro lugar, consideremos o cenário mexicano. A geografia desse país apresenta grandes extensões de terras áridas, improdutivas. Nessas regiões, não há como plantar e, por conseguinte, como desenvolver e manter a vida. Em meio à secura e à aridez da terra, os indivíduos andam lado a lado com a morte. Além das configurações inóspitas apresentadas em determinadas regiões, com os combates travados na revolução mexicana e na Guerra Cristera, alguns povoados - erigidos em áreas que se mostravam, em alguma instância, férteis - pereceram: muitos homens morreram nos enfrentamentos, restando apenas mulheres, crianças e velhos, ou seja, reduzindo a força produtiva do local.

Em segundo lugar está a instituição do purgatório. Ao implantar a doutrina do purgatório, a Igreja Católica criou a possibilidade da passagem da destruição física desenfreada que ainda estava presente (mas em um escala muito reduzida se comparada com os primeiros embates entre espanhóis e indígenas) à administração da morte. A proposição do purgatório estabelece um espaço entre dois extremos (céu e inferno). Para os espanhóis, a apresentação do purgatório como uma "opção" pós-morte mostrava-se muito atraente desde o dia em que puseram os pés no continente americano e

\footnotetext{
7 Tradução nossa: "a história do México possui uma qualidade fragmentária; é uma história com um claro antes e depois - ou seja, ora é pré-colombiana, ora é moderna - e a história moderna do México reflete e refrata essa fragmentação".
} 
cometeram assassinatos em grande escala, atos de ambição, de luxúria e de cobiça pecados inafiançáveis frente ao catolicismo. Ao praticar tais atos, os espanhóis configuraram-se como corruptores da inocência indígena - pecados da conquista. É provável que as gerações posteriores aos primeiros espanhóis que chegaram ao México estiveram menos marcadas pelo arrependimento, pela culpa e pelo temor ao castigo divino, uma vez que as estruturas e a propriedade das terras foram estabilizadas.

Em terceiro lugar está a constituição de um panteão nacional no qual convivem inimigos. Sem um herói que se sobressaísse, o Estado mexicano constituiu um panteão com indivíduos que, em grande parte, morreram uns pelas mãos dos outros, ou seja, o panteão nacional é constituído por uma série de inimigos mortais. Tal constituição traz para o interior do panteão a morte, pois somente nela a convivência entre tais opostos é possível.

$E$, em último lugar está a manutenção de concepções pré-colombianas no que concerne à morte. Os sacerdotes católicos eram conscientes de que os índios podiam dissimular suas antigas crenças e rituais relativos aos mortos e seguir praticando-os sob o disfarce dos rituais cristãos, em particular por meio das oferendas aos mortos. A igreja tolerava os costumes indígenas sempre que eles não contrapusessem princípios religiosos importantes. Cobrava menos dos índios e admitia certas manifestações a fim de não perder a possibilidade de, com o passar do tempo, efetivamente doutriná-los.

A concepção de purgatório associada aos "días de muertos" mexicanos, à estruturação do cenário natural mexicano, à constituição de um panteão nacional de inimigos mortais, além das inúmeras perdas humanas ocasionadas, em primeira instância pelos espanhóis no período de ocupação do território e, em segunda instância, pela revolução auxiliaram de forma profícua na estruturação da morte como um símbolo nacional. Mas, na qualidade de símbolo mexicano, a morte carrega consigo uma característica que parece, inicialmente, não estar de acordo com esses elementos: a alegria. A morte é comumente representada como um esqueleto brincalhão, maleável e, frequentemente, vestido. O México aparenta ter configurado o tema da intimidade popular com a morte como algo positivo: "Cuando los mexicanos hablan de su vínculo peculiar con la muerte, por lo general no se refieren al sacrificio de sus héroes muertos, sino a la 
relación de coqueteo y seducción por ambas partes"8 (LOMNITZ, 2006, p. 37).

Para Carlos Monsiváis (1987), a origem da imagem de intrepidez do mexicano frente à morte surgiu durante a revolução mexicana, período em que se fez uma grande publicidade em relação à atitude estoica frente às esquadras de fuzilamento. Porém, Monsiváis (1987) defende que tal estoicismo não era um traço peculiar do mexicano, não estando associado a qualquer crença pré-hispânica, mas estava, sim, relacionado ao desejo de arrebatar dos assassinos o seu triunfo adicional de ver a humilhação das vítimas. De acordo com o estudioso, no período posterior à revolução, um grupo de intelectuais, encabeçados por Octavio Paz, teria criado o mito do mexicano que ri da morte e se apropria de histórias de bravata frente a ela.

As afirmações de Monsiváis estão relacionadas ao momento em que a morte se erige como um totem nacional, mas não consideram a totalidade histórica do México e os elementos que motivaram essa eleição. Além disso, em El labirinto de la soledad, Octavio Paz disserta sobre um sentimento que se estende para além do período de revolução, abandonando o jocoso para entrar no pesaroso: a solidão do mexicano, a falta de encontrar um lugar, uma filiação:

La historia de México es la del hombre que busca su filiación, su origen. Sucesivamente afrancesado, hispanista, indigenista, pocho ${ }^{9}$, cruza la historia como un cometa de jade, que de vez en cuando relampaguea. En su excéntrica carrera ¿qué persigue? Va tras su catástrofe: quiere volver a ser sol, volver al centro de la vida de donde un día - ¿en la Conquista o en la Independencia? - fue desprendido. Nuestra soledad tiene las mismas raíces que el sentimiento religioso. Es una orfandad, una obscura consciencia de que hemos sido arrancados del Todo y una ardiente búsqueda: una fuga y un regreso, tentativa por restablecer los lazos que nos unían a la creación ${ }^{10}$. (PAZ, 1998, p. 06)

\footnotetext{
${ }^{8}$ Tradução nossa: "Quando os mexicanos falam de seu vínculo peculiar com a morte, de forma geral não se referem ao sacrifício de heróis mortos, mas sim à relação de cortejo e sedução de ambas as partes".

9 Pocho: termo empregado no México para filho de pais mexicanos nascido nos Estados Unidos ou mexicano que adota os costumes e os hábitos estadunidenses.

10 Tradução nossa: "A história do México é a do homem que busca sua filiação, sua origem. Sucessivamente afrancesado, hispanista, indigenista, pocho, cruza a história como um cometa de jade, que de vez em quando relampeja. Em sua excêntrica jornada, o que persegue? Vai atrás de sua catástrofe: quer voltar a ser sol, voltar ao centro da vida de onde um dia - na Conquista ou na Independência? - foi arrancado. Nossa solidão tem as mesmas raízes que o sentimento religioso. É uma orfandade, uma obscura consciência de que fomos separados do Todo e uma ardente busca: uma fuga e um regresso, tentativa de restabelecer os laços que nos uniam à criação".
} 


\section{Literatura e Autoritarismo}

Identidade, memória e representações culturais

Esse sentimento (a solidão) se relaciona intimamente com a eleição da morte enquanto totem nacional e se relaciona com a busca da identidade, com a tentativa de reconhecer-se. Sem um lugar definido, sem nada que possa perder, sem identificação com um grupo, a morte já não assusta tanto, configurando-se em uma companheira de trajeto. Entre os sentimentos de solidão e de alegria, as representações da morte nascem ambíguas, presas entre tantos recantos que as originaram, impossibilitadas de transcender. Então, qual a significação da morte? Sem ser trânsito, configura-se como "una boca vacía"11 (PAZ, 1998, p. 22), sem ser fartura e fertilidade, é seca e árida. Árida e vazia, por que a morte seduz o mexicano? A morte aparece como uma espécie de vingança contra a vida, destituindo esta de todas suas colorações e festividades e apresentando-a como um monte de ossos. Assim, destituída de beleza, a vida rememora todas as mortandades ocorridas no cenário mexicano, todas as perdas, sejam de terras ou de vidas humanas, e as amarra ao purgatório como um lugar de resignação, sem perspectiva. Os mortos recordam seus pecados presos ao passado. O presente também é passado e o futuro também o será. A morte, então, ganha as cores da vida, mas estas não possuem vitalidade e se perdem sem capacidade de transcender: "calaveras de azúcar o de papel de China, esqueletos coloridos de fuegos de artificio, nuestras representaciones populares son siempre burla de la vida, afirmación de la nadería e insignificancia de la humana existência"12 (PAZ, 1998, p. 23).

Ao manter a morte como um símbolo constante, o mexicano mostra que "no quiere ser ni indio, ni español. Tampoco quiere descender de ellos. Los niega. Y no se afirma en tanto que mestizo, sino como abstracción: es un hombre. Se vuelve hijo de la nada. Él empieza en sí mismo"13 (PAZ, 1998, p. 36). Assim definido, como ruptura e como negação, mantém ainda a busca no intuito de superar esse estado de exílio, por isso vinga-se da vida, pois esta parece impedi-lo, parece lhe sinalizar a consciência de sua solidão histórica e pessoal - enquanto ser humano, abandonado por Deus, expulso do paraíso, sem lar.

\footnotetext{
${ }^{11}$ Tradução nossa: "uma boca vazia".

12 Tradução nossa: "caveiras de açúcar ou de papel de seda, esqueletos coloridos de fogos de artifício, nossas representações populares são sempre burla da vida, afirmação da ninharia e insignificância da existência humana".

${ }^{13}$ Tradução nossa: "não quer ser nem índio nem espanhol. Tampouco quer descender deles. Nega-os. E não se afirma como mestiço, mas sim como abstração: é um homem. Se converte em filho do nada. Ele começa em si mesmo".
} 
Ter a morte como totem implica colocar todos os mexicanos sob a mesma égide, todos seguem a mesma busca - ainda que essa pareça nunca produzir frutos promovendo uma espécie de reconciliação coletiva provisória: ninguém escapa da morte e, se ela é inevitável, que seja tratada com a intimidade dispensada aos amigos sempre presentes. Com essa intimidade estabelecida, o pacto social sofre algumas alterações. A morte seria o momento em que as faç̧ões opostas se reconciliariam (como no panteão nacional mexicano) estabelecendo um pacto social baseado no que Lomnitz (2006) chama de reciprocidad negativa: "la unidad y solidaridad entre los mexicanos surge a pesar del origen de la nación en la violación y el pillaje de la conquista y sus repeticiones cíclicas a todo lo largo de la historia moderna, que culmina con la revolución mexicana"14 (LOMNITZ, 2006, p. 47).

\section{A morte em Pedro Páramo}

Em Pedro Páramo, a morte não apresenta faces jocosas, mas sim traços duros. Contudo, ainda configura-se como uma amiga com a qual é inevitável conviver, da qual não se pode escapar. No romance, a morte, de forma geral, e os mortos, de forma particular, não são passivos. Intranquilos, eles devolvem aos vivos o olhar que estes thes lançam, trocando histórias, mas sem nunca realmente alcançarem o diálogo, a comunicação, a conciliação: cada personagem narra só a sua história e não consegue apreender as dos demais. Todas as histórias pertencem ao passado: Juan Preciado traz para o povoado fragmentos das suas vivências com Dolores, fragmentos de um tempo anterior; os mortos de Comala não fazem planos, não projetam o futuro, apenas possuem relatos do passado. O presente irrompe como passado na narrativa. Vivos e mortos se reconhecem sem perspectivas, sem projeções, marcados por acontecimentos anteriores, atrelados a estes - Juan está preso à promessa feita a sua mãe, está atrelado aos relatos que ela fazia de Comala, a uma figura paterna descrita por ela; Eduviges está presa a uma existência de tormentos, a conversas com mortos (sendo ela um deles), ao seu trabalho na estalagem, e assim estão, também, os demais.

\footnotetext{
${ }^{14}$ Tradução nossa: "a unidade e a solidariedade entre os mexicanos surge apesar da origem da nação na violação e na pilhagem da conquista e suas repetições cíclicas ao longo de toda a história moderna, que culmina com a Revolução Mexicana".
} 


\section{Literatura e Autoritarismo}

Os vivos parecem condenados (ninguém escapa da morte) ou mesmo estar mortos. Os vivos e os mortos se reconhecem uns aos outros, se medem, se avaliam como parte do passado. Assim como os mortos rondam a vida com seus olhares, os vivos são esqueletos com conhecimento de causa, tocados já pela morte, de antemão já são obsoletos. Quando os mortos e os vivos se reconhecem, se identificam, estes últimos acabam por distanciarem-se da época em que vivem, sentindo que já não se identificam com ela.

Ao empregar mortos como personagens, Rulfo fez uso de um dos totens mexicanos. Na narrativa, percebemos que a configuração da morte assume perspectivas que podem ser associadas com os aspectos que discutimos aqui como, por exemplo, a jocosidade e a solidão. A primeira pode ser percebida em trechos como:

-(...) Con usted debe haber pasado lo mismo, ¿no?

-No me acuerdo.

-¡Váyase mucho al carajo!

-¿Qué dice usted?

-Que ya estamos llegando, señor. ${ }^{15}$ (RULFO, 2009, p. 9)

Na conversa entre Abundio e Juan Preciado, o primeiro, já morto, tem a liberdade de burlar-se do segundo. Essa liberdade foi conquistada pelo fato de que o arrieiro possui conhecimentos sobre Pedro que Juan ainda não possui e, na condição de morador de Comala, conhece a história que o filho de Dolores busca saber. Além disso, a morte o libertou das normas sociais às quais Juan ainda está preso. Livre de imposições, Abundio faz uso da jocosidade em sua fala.

Há, ainda, o sentimento de solidão, de não pertencimento que está manifesto em Susana San Juan, "una mujer que no era de este mundo" (RULFO, 2009, p. 115). Sem encontrar seu lugar neste mundo, Susana não pertence a nenhum espaço terrenal. Sem crer em Deus, está sujeita a uma solidão ainda maior. A morte, então, surge como sua amiga, envolvendo-a, confortando-a em um mundo de perdas. Mas, essa amiga não lhe

\footnotetext{
${ }^{15}$ Tradução nossa:

“-(...)Com o senhor deve ter passado o mesmo, não?

-Não me lembro.

-Vá ao caralho!

-O que o senhor disse?

-Que já estamos chegando, senhor".
} 
traz promessas de uma transcendência, apenas se projeta como uma companheira de jornada.

A morte irrompe na estrutura textual de Pedro Páramo como um elemento mexicano, como um símbolo nacional. Seu emprego na narrativa permite a elaboração de uma proposta de interpretação que atualiza dentro do texto literário - em sua organização - o passado histórico mexicano, propondo uma constituição do presente que repensa o processo vivenciado pelo país desde a chegada dos espanhóis até a revolução mexicana. Contudo, o texto de Rulfo rompe com o frágil pacto social e nega qualquer possibilidade harmônica de convivência, negando, também, a transcendência. O mexicano solitário, após a revolução, não conseguiu adotar a Modernidade como um projeto próprio, consequentemente não podia construir a sua própria transcendência, pois não possuía um futuro claro, visto que o catolicismo e as crenças indígenas estavam desmoronando no novo panorama cultural.

\section{Considerações Finais}

Deparar-se com Pedro Páramo pela primeira vez, encontrar uma cidade fantasma habitada por personagens mortas cujas vozes e atitudes ainda estão presentes no ambiente que habitam causa certa estranheza. O realismo mágico poderia facilmente servir de explicação para tal construção literária. Entretanto, a morte no romance de Rulfo vai além das características presentes no realismo mágico. Ela ingressa na estrutura identitária mexicana, revolvendo séculos de história, atrelando-se a aspectos geográficos, encontrando-se na fusão de indígenas e europeus. Tratar da morte em Pedro Páramo é tratar da construção das personagens, do cenário, do enredo. A morte se faz presente como algo interno à narrativa que, ao mesmo tempo, estabelece relações para além do romance, alcançando a sociedade, a cultura mexicana.

As personagens mortas estão equiparadas, igualadas: todas presas a Comala, elas enfrentam suas penas em um purgatório que as condenou a repetir infinitamente os atos que cometeram em vida. As casas em ruínas, a falta de produção e a aridez da terra anunciam a impossibilidade do estabelecimento de novas vidas, de alimento, de 
produtividade no povoado. O enredo abre com a morte de Dolores e encerra com a morte de Pedro, elencando a morte de tantos outros habitantes de Comala e de Juan Preciado entre as duas. Contudo, em meio a esse cenário, os mortos de Comala seguem reivindicando um espaço. Eles querem ser ouvidos, querem contar suas histórias, querem atualizá-las no presente através da figura de Juan Preciado. O filho de Dolores as escuta em um ato de recuperação, de retomada do passado junto ao presente. Quando Juan morre, integrando-se ao povo de Comala, a morte afirma-se como uma companheira de todos, como "integrante" da identidade e da existência de todos que estão no povoado. Não há transcendência, nem projeções para o futuro. Há, sim, o presente e o passado como campos de atuação das personagens. E, nesses campos, o pacto social não foi capaz de igualar todos os habitantes de Comala mesmo após a morte desses. Há personagens, como Pedro Páramo e o cura Rentería, que não estão entre os mortos apresentados na narrativa, mas cuja existência segue sendo referenciada pelas demais personagens.

A morte não alterou a estrutura social da vida, permitindo que sejam feitas analogias: morte e vida são similares, o que nos leva a indagar se as personagens já estavam mortas em vida? Nesse caso, o sentimento de solidão, de não pertencimento sobre o qual falava Octavio Paz (1998) pode ser empregado como um elemento que auxilia na compreensão da estruturação da morte no romance de Rulfo: todos os que vivem em Comala estão sujeitos à morte, todos compartilham da mesma solidão. $A$ solidão fica visível na dificuldade que as personagens têm para se comunicarem (não há diálogos, elas apenas informam umas às outras suas histórias). A sedução da morte, no romance, fica por conta da possibilidade de evasão, da busca por outro caminho. Susana San Juan via na morte uma possibilidade de abandonar a vida ausente de felicidade que experienciava em Comala. Já Eduviges vai ao extremo em busca da morte: ela cometeu suicídio. Mas, mesmo mortas essas personagens não parecem felizes. Ao contrário, a morte e a vida de ambas se assemelham muito, fazendo com que a solidão e o sentimento de abandono se perpetuem. Tal perpetuação estabelece uma crítica à revolução mexicana que buscou criar um "espaço" para o mexicano, permitindo-lhe ocupar efetivamente seu próprio país, mas que, nas páginas de Pedro Páramo, parece ter fracassado em seu intuito, reproduzindo na morte (no período pós-revolucionário) as agruras da vida. 


\section{Referências}

BERNAND, Carmen; GRUZINSKI, Serge. História do Novo Mundo 2: as mestiçagens. Tradução Mary Amazonas Leite de Barros. São Paulo: Editora da Universidade de São Paulo, 2006.

KLAHN, Norma. La ficción de Juan Rulfo: nuevas formas del decir. In: Fell, Claude (Coord.). Juan Rulfo. Toda la obra. Edición crítica. 2. ed. Madrid: ALLCA XX, 1996. p. 521-529.

LOMNITZ, Claudio. Idea de la muerte em México. Tradução Mario Zamudio Vega. Ciudad de México: Fondo de Cultura Económica, 2006.

MANZUR, Carlos Azar. El teatro del poder (Texto en dos actos y un envío). In: ROSAS, Alejando (Coord.). Las dos caras de la historia: Revolución Mexicana: El tiempo del caos. Ciudad de México: Grijalbo, 2011. p. 363-394.

MONSIVÁIS, Carlos. "Mira muerte, no seas inhumana": notas sobre un mito tradicional e industrial. In: POMAR, Maria Teresa. El día de los muertos. The life of the dead in Mexican Folk Art. Fort Worth: The Fort Worth Art Museum, 1987. p. 09-16.

PAZ, Octávio. El laberinto de la soledad. Madrid: Fondo de Cultura Económica de España, 1998.

RULFO, Juan. Pedro Páramo. Santiago de Chile: Editorial RM, 2009. 